\title{
SANTILLANA, GARCILASO Y EL EPODO II
}

\author{
Alvaro Alonso de Miguel \\ Universidad Complutense
}

Ignorado prácticamente a lo largo de la Edad Media, el Epodo // de Horacio conoce a partir del siglo $X V$ una fortuna que apenas admite comparación con la de otros textos clásicos. Los mayores escritores del Siglo de Oro - Herrera, fray Luis, Góngora- vuelven una y otra vez sobre las tradicionales alabanzas del usurero Alfio, traduciéndolas o adaptándolas con mayor 0 menor libertad $^{\prime}$. En lo que sigue me propongo analizar dos de las más antiguas y conocidas versiones del motivo clásico, con objeto de señalar sus semejanzas y sus diferencias, pero, sobre todo, de clarificar algunas cuestiones relativas al significado del tópico.

Es bien sabido que la primera versión castellana del Beatus ille aparece en la Comedieta de Ponza, del Marqués de Santillana, quien la pone en boca de la infanta doña Catalina ${ }^{2}$. Tal y como aparece en este texto del Marqués, el pasaje contiene el elogio de dos grupos sociales, el de los campesinos y los pescadores, caracterizados por su exclusión del poder y la riqueza. En el Epodo II, esa situación no supone necesariamente miseria, y ni siquiera excluye un cierto bienestar material; pero, frente a su modelo, Santillana describe condiciones más duras, y no deja de mencionar las «lluuias e vientos» que tienen que padecer los labriegos, ni las «pobres traynas» de los pescadores.

Más dificil resulta la caracterización social de los personajes mencionados en la estrofa XVII:

1 Noël Salomon: Lo villano en el teatro del Siglo de Oro, Madrid, Castalia, 1985, pp. 165 y ss.; María Rosa Lida de Malkiel: "Horacio en la literatura mundial", en su libro La tradición clásica en España, Barcelona, Ariel, 1975, pp. 253-267.

2 La adaptación del Marqués de Santillana ha sido objeto de un estudio de Félix Carrasco: "Aproximación semiótica al "Benditos aquéllos..." del Marqués de Santillana", RLit, XLV (1983), pp. 5-19. Cf. también Rafael Lapesa: Los decires narrativos del Marqués de SantiIlana, Madrid, Real Academia Española, 1954, pp. 53-56; del mismo autor La obra literaria del Marqués de Santillana, Madrid, Insula, 1957; Arnold G. Reichenberger: "The Marqués de Santillana and the classical tradition", IR, I(1969), pp. 5-34. Mis citas del texto corresponden siempre a Íñigo López de Mendoza: La Comedieta de Ponzq, ed. Maximiliaan P. A. M. Kerkhof, Groningen, Rijksuniversiteit, 1976. 
iBenditos aquellos que siguen las fieras

con las gruessas redes e canes ardidos,

e saben las trochas e las delanteras

e fieren del archo en tienpos deuidos!

La referencia es ambigua, ya que los tratados de la época suelen diferenciar dos tipos de caza: la que se practica con fines utilitarios, y la que los hombres siguen "por deporte e solaz e alegría de sus spíritus e por exercitar sus personas» ${ }^{3}$. ¿A cuál de las dos se refiere la Comedieta? $6 \mathrm{Al}$ modesto cazador que vive de lo que consigue, o al noble que interviene en una partida? En el segundo caso se trataría de un personaje de clase muy distinta a los anteriores, y su exclusión del poder sería voluntaria y, probablemente, pasajera: especie de descanso en la vida de un gran señor, muy distante, por lo demás, del ideal horaciano. Evitaré de momento las dificultades que suscita esa interpretación, y supondré una cierta homogeneidad en la categoría de los personajes ${ }^{4}$.

A esa caracterización social se acompaña otra psicológica, definida básicamente por tres rasgos:

1. La ausencia de temor: "Ca estos non temen los sus mouimientos» (v. 125); «nin turban themores sus libres sentidos» (v. 136); «Ca estos non temen las lides marinas» (v. 143).

2. La conformidad con la propia suerte y la falta de ambiciones:

Ca estos por saña non son comouidos, nin vana cobdiçia los tiene subiectos; non quieren thesoros, nin sienten deffectos (vw. 133-136).

3. La ignorancia:

nin saben las cosas del tienpo passado, nin de las presentes se fazen cuydado, nin las venideras do han nascimientos. • (vv. 126-128).

3 Rodrigo Sánchez de Arévalo: Vergel de los principes, en Prosistas castellanos del siglo XV, I, ed. Mario Penna, Madrid, Atlas, 1959 (BAE, CXVI), p. 327a.

4 Los vv. 137-140 se refieren probablemente a los pajarero aunque tampoco me resultan absolutamente claros. 
Pero lo definitorio de la Comedieta, como del Epodo, es que concibe en términos de espacio esas características sociales y psicológicas. Hay un territorio del poder y otro de la medianía; uno de la serenidad, y otro de la ambición y la angustia. Se crea así una especie de topografia de las pasiones, que preserva a ciertos ámbitos de su presencia, y condena a otros a su tiranía. La Comedieta esboza esa concepción que recluye la codicia y el temor dentro de los muros de la ciudad ${ }^{5}$, y libera al campo de su dominio: el "llugar» de la felicidad es, ante todo, una posición social -la de los labradores y los pescadores-, pero también, y aunque sólo fuera de rechazo, el territorio que todos ellos habitan. El Beatus ille es algo más que la alabanza de la probreza; es la alabanza de ese estado más una ambientación campesina o rural:

\section{Caracterización social}

1a. Exclusión de la riqueza y el poder: pobreza o mediania

\section{psicológica \\ espacial}

2a. Ausencia de temor

2b. Ausencia de ambición

2c. Ignorancia 3a. Campo 0 aldea situada en

Convendrá detenerse ahora en las relaciones causales que se establecen entre todos los términos en juego. En primer lugar, es posible suponer que el ignorante vive en un estado de inconsciencia feliz, ya que su propia rudeza lo aparta de la ambición y el miedo. La idea no es rara entre los contemporáneos de Santillana y Fernán Pérez de Guzmán la recoge en sus Coplas de vicios e virtudes:

\section{El discreto e sabidor siempre viue temoroso, viue el torpe e perezoso alegre e a su sabor}

El sabio siente los daños incluso antes de que lleguen, en tanto que "dormirá a pierna tendida/ el torpe dando ronquidos", aun cuando se derrumben los cielos y se estremezca la tierra ${ }^{6}$.

Los términos $2 \mathrm{a}$ y $2 \mathrm{~b}$ serían, por tanto, la consecuencia inmediata de $2 \mathrm{c}$, que, a su vez, aparece como resultado casi inevitable de la bajeza social. De tal forma que sería posible establecer la siguiente cadena causal ${ }^{7}$ :

5 En la Comediera es más bien el palacio el elemento negativamente marcado (Cf., por ejemplo, los vv. 452-454). No obstante, el territorio de los poderosos es menos identificable que en otras versiones del Epodo, donde, en cualquier caso, suele aparecer más desdibujado que el espacio de la pobreza.

"Fernán Pérez de Guzmán: "Amigo sabio e discreto", en Raymond Foulché-Delbosc: Cancionero castellano del siglo xv. I, Madrid, Bailly-Baillière, 1912 (NBAE, 19), p. 616b.

7 Tal parece ser la interpretación de Kerkhof en su edición citada p. 358. 
1a. Pobreza

Pero existe una segunda interpretación, que me parece más obvia en el contexto de la Comedieta: siendo así que los pobres no tienen nada que perder, están a salvo de la Fortuna y del temor hacia ella: «Ca estos non temen las lides marinas,/nin çierra sobr'ellos Fortuna sus llaues" (vv. 143-144).

Por lo que hace a la ambición, es posible suponer que el deseo aumenta a medida que se satisface, de tal manera que son justamente los más necesitados quienes menos ambicionan ${ }^{8}$. Es decir:
Caracterización social
psicológica
espacial
1a. Pobreza
2a. Ausencia de temor
Ausencia de ambición
3a. Campo

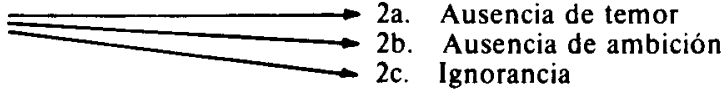

Se observará que, en uno y otro caso, las relaciones entre el campo y la serenidad son meramente indirectas y accidentales: es la condición social de los rústicos, y no su contacto con la naturaleza, lo que los salva de la zozobra de los poderosos. No obstante, un episodio posterior de la Comedieta sugiere aún una tercera explicación. Agobiada por la incertidumbre, la reina se retira "a vna arboleda de frondes sonbrosa», donde encuentra cierto alivio a su ansiedad:

Ya de los temores cessaua el conbate

al animo afflicto, e yo reposaua

segura e quieta: de ningund rebate

nin otro infortunio ya me temoraua.

(vv. 385-388)

En esta ocasión, no cabe atribuir la quietud a la condición social del personaje, y sí únicamente del espacio donde se mueve. A pesar de estar colocada en el lugar más alto de la jerarquía social, y sometida a toda suerte de riesgos, la reina encuentra la calma por el mero hecho de salir al jardín.

A la vista de ese episodio, cabe pensar que Santillana atribuía un efecto serenador a la Naturaleza por sí misma, y con independencia de cualquier otra consideración. En el mismo pasaje del «Benditos aquellos», da la im-

8 Bastará el testimonio del propio Marqués: “Que quanto más adquirieres, / más querrás" (Proverbios, $L X X I I)$. 
prensión de que los cazadores escapan a la pasión mediante el simple alejamiento de la corte y el extravío en el espacio del bosque:

\section{Caracterización social}

1a. Pobreza

\section{psicológica}

2a. Ausencia de temor

2b. Ausencia de ambición

2c. Ignorancia

espacial

Si eso es así, el campo ha dejado de ser mero escenario de una serena pobreza, $y$ se ha convertido en elemento activo, responsable en parte de esa misma serenidad que alberga.

Las relaciones causales que he esquematizado en los cuadros anteriores no son necesariamente incompatibles, y a mi modo de ver, las tres funcionan simultáneamente en la Comedieta, reforzándose:

\section{Caracterización social}

la. Pobreza

\section{psicológica}

Ausencia de temor Ausencia de ambición Ignorancia espacial

3a. Campo

El motivo del Beatus ille se presenta así como una articulación de varios elementos entre los que se establecen relaciones complejas, si bien las que el texto destaca son las que unen 1 a 2 . Cuando del texto de Santillana se pasa a la Égloga II de Garcilaso, es posible advertir varias diferencias de interés:

1. Una mayor idealización en el personaje del que se predica el beatus ille. En la égloga, los campesinos y su trabajo han sido sustituidos por un pastor literario, que cuenta su ganado «a la sombra holgando/d' un alto pino o robre) (vv. 51-52)

2. Una mayor voluntariedad por parte de ese mismo personaje. En dos ocasiones da la impresión de que su situación es escogida y no forzada, es decir, de que nos encontramos ante un cortesano que ha decidido retirarse del mundo: «iCuán bienaventurado/ aquél puede llamarse/ que con la dulce soledad s'abraza», «y como está en su seso, / rehuye la cerviz del grave pe-

9 Cito siempre por Garcilaso de la Vega: Poesias castellanas completas, ed. Elias L. Rivers, Madrid, Castalia, 1969. Sobre el pasaje cf. Rafael Lapesa: La trayectoria poética de Garcilaso, Madrid, Revista de Occidente, $1968^{2}$, pp. 102 y ss. 
so" (vv. 38-40 y 62-63). No obstante, esa circunstancia no altera los elementos fundamentales del tópico, ya que de manera más o menos deliberada, el personaje sigue excluido del poder y la riqueza.

3. La eliminación de cualquier referencia a la ignorancia o la insensibilidad del pastor.

4. El énfasis en los aspectos morales del problema. En la obra de Santillana, no faltaban referencias de esa naturaleza, como la mención a la codicia de los vv. 134-135. Por otro lado, el esquema de todo el pasaje recuerda a las bienaventuranzas evangélicas ${ }^{10}$, lo que proyecta a los rústicos y su modo de vida en una atmósfera de superioridad moral. No obstante, el eje sobre el que siguen oponiéndose campo y corte es el de la felicidad y no el de la virtud. Convendrá no pasar por alto que el texto está puesto en boca de Catalina, quien enfrenta la suerte envidiable de los rústicos a la suya y la de los reyes. En esa antítesis básica, la infanta podía deplorar la suerte de los segundos, dificilmente condenarla. En cambio, en el texto de Garcilaso las consideraciones éticas adquieren más importancia, aún sin llegar a los extremos de fray Luis. Los personajes que sirven de término de comparación, aquellos sobre los que se destaca la figura del pastor, no son los soberanos derrotados en Ponza, a los que no puede hacerse ningún reproche. Ni son tampoco, genéricamente, los poderosos. Los vv. 44-50 dibujan el perfil más preciso de un cortesano hipócrita y adulador, dos defectos que no aparecen para nada en la Comedeta. Siendo básicamente idénticas, las dos antitesis presentan ligeras variaciones: campesinos.../ reyes, pastor/ cortesano.

Pero sin duda, la diferencia más importante es el mayor espacio dedicado a la descripción de la naturaleza. Esa atención sugiere ya que Garcilaso intensifica ciertas conexiones causales (las que unen 3 a 2), apenas insinuadas en la Comedieta. Más explícitamente, Albanio reconoce el poder serenador de la Naturaleza, en un monólogo que precede a la larga tirada de Salicio:

El dulce murmurar deste rüido, el mover de los árboles al viento, el suave olor del prado florecido podrian tornar d'enfermo y descontento cualquier pastor del mundo alegre y sano; yo solo en tanto bien morir me siento. (vv. 13-18)

10 Rafael Lapesa: Los decires narrativos..., ob. cit., p. 55. 
Y más adelante, el propio Salicio:

Convida a un dulce sueño

aquel manso rüido

del agua que la clara fuente envia,

los árboles, el viento,

al sueño ayudan con su movimiento.

(vv. 64-76)

Feliz por su marginalidad social con respecto a los poderosos, el pastor lo es también, y sobre todo, por vivir en un espacio propio, alejado de la corte, y concebido como su reverso.

Ese territorio, social y espacialmente definido, en el que se mueven los personajes, constituye, como veíamos, una suerte de refugio contra la Fortuna. En el De remediis, Petrarca veía un solo camino para escapar al poder de la diosa:

De manera que solos aquellos que entran por la puerta de la sepultura son seguros de los sobresaltos desta vida"l.

Santillana, en cambio, concibe el campo como región feliz entre la puerta de la sepultura y los sobresaltos de la vida, tierra de nadie entre el dominio de la muerte y el de la Fortuna. En otro pasaje del De remediis se establece una significativa relación entre la vida retirada y la vejez. Un viejo romano se resiste a abandonar los trabajos públicos de la audiencia, y la Razón se burla de él, amonestando:

Aprender podrás de los philósophos qué cosa sea y cuán déseada de los buenos viejos bivir, como dizen, después de la vida acabada ${ }^{12}$.

11 Cito por la traducción castellana De los remedios contra próspera y adversa fortuna, Valladolid, 1510, fol. cV rto.

12 Idem, id., fol. y VIl vto. 
En la Comedieta son los cazadores, los campesinos o los pescadores quienes disfrutan de ese privilegio de vivir al margen de la vida misma, casi al filo de la muerte; son una clase y un lugar, en vez de un grupo caracterizado por su edad.

Pero cuando ese «lugar» es inaccesible, como para doña Leonor, sólo queda añorarlo, $y$ buscar refugio en el otro que se halla a salvo del azar. Entre la muerte de la reina y la alabanza de la vida retirada existe una relación más estrecha de lo que pudiera parecer.

De una manera diferente, esa relación aparece también en la égloga de Garcilaso. Apenas ha terminado su alabanza de la vida retirada, Salicio descubre el cuerpo dormido de Albanio, lo que le da pie para un elogio del sueño, que termina con toda naturalidad en una reflexión sobre la muerte:

\begin{abstract}
¿Quién duerme aqui? ¿Dó está que no le veo? iOh, hele alli! iDichoso tú, que aflojas la cuerda al pensamiento o al deseo!

Duerme, garzón cansado y afligido.

iPor cuán mejor librado tengo un muerto, que acaba 'l curso de la vida humana y es conducido a más seguro puerto, qu'el que, viviendo acá, de vida ufana y d'estado gozoso, noble y alto es derrocado de fortuna insana!
\end{abstract}

(vv. 77-106)

No es dificil justificar ese deslizamiento, atendiendo a la idea del sueño como imagen y anticipo de la muerte. Pero parece claro que en ese contexto tampoco la versión del Beatus ille puede aislarse de los otros dos motivos: la "dulce soledad» es también una imago mortis, y su alabanza sirve aquí de preludio a las otras dos. Como el sueño, el campo «afloja la cuerda al pensamiento o al deseo", si bien en una esfera diferente, la de los temores y las ambiciones cortesanas. "Belle dame sans merci», la corte parece ofrecer y deniega, parece prometer y defrauda.

Sólo que esos «pensamientos y deseos» se atenúan en contacto con la Naturaleza, mientras que los amorosos, al menos en el caso de Albanio, no admiten ese alivio ("yo solo en tanto bien morir me siento»). Es preciso entonces intentar el segundo camino («en tus manos ioh sueño! m'encomiendo) y, en el límite, el último (deseo de morir de Albanio). El triple elogio de Salicio es, por consiguiente, una gradación, en la que va intensificándose la idea de evitar la inquietud. En la égloga, como en la Comedieta, la versión del Beatus ille apunta una solución, pero termina declarándola insuficiente o imposible para el personaje. 